\title{
Effect of Various Injection Speeds of Propofol on Blood Pressure, Time Taken and Dose Required for Induction of Anesthesia: A Prospective Observational Study
}

\author{
Bhat KA, Bhat JA*, Ara R and Sidiq S \\ Paras Hospital Gurugram, India
}

*Corresponding author: Jehangir Allam Bhat, Paras Hospital Gurugram India, Tel: +917033203315; Email: ajaalam333@gmail.com

\section{Research Article}

Volume 3 Issue 3

Received Date: July 17, 2018

Published Date: August 08, 2018

\section{Abstract}

Background: To investigate the effect of injection speed of Propofol for induction of anesthesia primarily on blood pressure and secondarily, on time taken for induction of anesthesia and dose of propofol required.

Methods: The prospective \& interventional, randomized single blind comparative study conducted on 90 patients of both sexes aged 25-55 years of ASA grade I/II admitted to Paras Hospital Gurugram India, a tertiary care Centre, for elective surgeries under general anesthesia.

Results: Mean age, sex, weight, height and distribution of patients as per ASA status was comparable among all the three groups as statistically $\mathrm{P}$ values were not significant (all P Value $=>0.05$ ). The differences of mean dose of Propofol used in $\mathrm{mg}$ and $\mathrm{mg} / \mathrm{kg}$ for induction, mean induction time (seconds), pre and post induction mean systolic blood pressure ( $\mathrm{mmHg}$ ), mean diastolic blood pressure $(\mathrm{mmHg})$ and mean arterial pressure ( $\mathrm{mmHg}$ ) among the studied groups (P50, $\mathrm{P} 100$, and inP200) were statistically significant with a $\mathrm{p}$ value of $<0.05$. There was no statistically significant difference between pre and post induction mean heart rate and oxygen saturation.

Conclusion: At faster speeds of injection of Propofol, larger doses are required for induction of anesthesia and significant drop in systolic, diastolic and mean arterial pressures while as the time taken for induction of anesthesia was shorter when compared to the injection at slower speeds.

Keywords: Propofol Injection Speed; Intravenous Anesthesia; Hypotension; Mean Arterial Pressure

\section{Introduction}

Propofol is preferred over Thiopentone sodium for induction of anesthesia but one of the disadvantages of
Propofol is significant hypotension. A typical induction dose of Propofol $2 \mathrm{mg} / \mathrm{kg}$ body weight results in approximately $30 \%$ reduction in systolic blood pressure [1]. The hypotensive effect of Propofol is attributable to a 


\section{Advances in Pharmacology and Clinical Trials}

decrease in sympathetic activity, direct vasodilatation and myocardial depression [2]. This fall in blood pressure is of little significance in normal healthy patients but can be of great significance in patients who have coronary artery disease etc. because it can lead to myocardial ischemia. Blood concentration of Propofol depends on many factors such as age, gender, body weight, dose, cardiac output and infusion rate [2-4].

The effect of different injection rates of Propofol on hemo dynamics, induction time and dose required for induction of anesthesia has been investigated in several studies [5-8]. In most of the studies it was observed that decrease in blood pressure was significantly less in patients in whom the drug was injected at a slower speed although there was a slight delay in induction time which was statistically significant and also there was a slight decrease in the dose of Propofol which was also statistically significant, for induction of anesthesia.

Dose requirements of Propofol induction depend on patient characteristics and infusion rate [8] Cardiac output (CO) is thought to be an important factor affecting the induction of anesthesia [9] Particularly high concentrations could be expected if a normal dose of Propofol was injected into a patient with low CO. Consistent with the experience of most anesthesiologists, critically ill patients with low CO usually require very small doses of Propofol [10].

The mechanism of hypotension is attributed to a decrease in sympathetic activity [11], myocardial depression [12], and direct vasodilation [12,13]. Hypotensive effects of Propofol are generally proportional to the dose and rate of administration $[12,14,15]$. Induction with Propofol is known to cause decrease in blood pressure. Studies have demonstrated up to a $28 \%$ decrease in SBP, an $11 \%$ decrease in MAP, and a $19 \%$ decrease in DBP $[12,16]$. When Propofol is administered as a $2 \mathrm{mg} / \mathrm{kg}$ IV bolus, SBP decreased by $20 \%$. There was also a decrease in DBP and MAP by $16 \%$ and $19 \%$ respectively. In a recent study, Cheng et al has proposed a molecular pathway that may contribute to vasodilatory effect of Propofol [17]. Due to the inhibitory effect of Propofol on barore flexes and sympathetic activity, the effect of Propofol on heart rate is variable with many studies showing decrease in heart rate $[18,19]$.

Several studies with varied methods of delivery have demonstrated reduced hemodynamic effects and a decrease in dose requirements of Propofol. Studies have also shown that a slower injection of Propofol decreases cardiovascular effects $[20,21]$. However, slow injection may also result in longer induction times. In a recent study using a target controlled infusion (TCI), Liu, et al. [22] demonstrated that the decrease in SBP was significantly less when Propofol was given in a step wise technique with an initial plasma concentration of 2.0 $\mathrm{mg} / \mathrm{ml}$ and then raised to a target plasma concentration of $4.0 \mathrm{mg} / \mathrm{ml}$ [23].

The objective in the present study is to investigate the effect of injection speed of Propofol for induction of anesthesia primarily on blood pressure and secondarily, on time taken for induction of anesthesia and dose of propofol required.

\section{Methodology}

The was prospective \& interventional, randomized single blind comparative study conducted on 90 patients of both sexes aged 25-55 years of ASA grade I/II admitted to Paras Hospital Gurugram India, a tertiary care Centre, for elective surgeries under general anesthesia after taking clearance from ethical and scientific committee and after obtaining an informed written consent from every patient. The mean age, weight, height and ASA Status was comparable among all the groups

\section{Inclusion Criteria}

- Patients in age group of 25-55 years

- ASA Grade I/II

- Elective surgeries

\section{Exclusion Criteria}

- Patients less than 25 and more than 55 years of age

- ASA Grade III/IV

- Emergency surgeries

- Known allergy to the study drug

- Patient's refusal to participate in the study.

- Hypertensive patients

- Diabetic patients

A detailed pre-anesthetic checkup including history, general physical examination, and routine investigations as guided by age were carried out in all patients. After shifting the patient to the operating room, multichannel monitors were attached to the patient for recording the vital parameters like fasting status, Systolic blood pressure, Diastolic blood pressure, mean arterial pressure, ECG, Heart rate, End tidal CO2 and Oxygen saturation. All these vitals were recorded as baseline parameters. 


\section{Advances in Pharmacology and Clinical Trials}

$1 \%$ Propofol was given in the form of injection manually using stop watch \& $20 \mathrm{ml}$ disposable syringe, at three different rates of $50 \mathrm{mg} / \mathrm{min}(1 \mathrm{ml} / 12 \mathrm{sec}$. $)$ to the patients of group $\mathrm{P} 50,100 \mathrm{mg} / \mathrm{min}(1 \mathrm{ml} / 6 \mathrm{sec}$.) to the patients of group P100 and $200 \mathrm{mg} / \mathrm{min}(1 \mathrm{ml} / 3 \mathrm{sec}$.) to the patients of group P200 respectively until the loss of verbal contact. After that fentanyl $(1 \mathrm{mcg} / \mathrm{kg})$ and atracurium $(0.5 \mathrm{mg} / \mathrm{kg})$ were administered and anesthesia was maintained with isoflurane in $50 \% \quad \mathrm{O}_{2}-\mathrm{N}_{2} \mathrm{O}$. Hypotension, time taken for induction and dose of Propofol (till loss of verbal contact) were compared among the three groups.

\section{Statistical Analysis}

Statistical analysis was done by SPSS Version 20.0 (SPSS Inc., Chicago, Illinois, USA). Continuous variables were expressed as Mean $\pm S D$ and categorical variables were summarized as frequencies and percentages. Analysis of variance (ANOVA) with least significant difference (LSD) test was employed for comparing continuous variables. Chi-square test or Fisher's exact test, whichever appropriate, was applied for comparing categorical variables. A P-value of less than 0.05 was considered statistically significant.

\section{Results}

In our study as illustrated in Table 1.

\begin{tabular}{|c|c|c|c|c|}
\hline & P50 & P100 & P200 & P Value \\
\hline Age (Years) & $37.6(28-52)$ & $40.1(26-55)$ & $39.2(25-55)$ & 0.546 \\
\hline Gender M/F & $14(46.7 \%) / 16(53.3 \%)$ & $17(56.7 \%) / 13(43.3 \%)$ & $16(53.3 \%) / 14(46.7 \%)$ & 0.732 \\
\hline Weight Kg & $68.3(57-79)$ & $69(58-77)$ & $68.5(53-80)$ & 0.898 \\
\hline Height & $163.2(154-174)$ & $162.1(156-168)$ & $163.8(157-175)$ & 0.338 \\
\hline
\end{tabular}

Table 1: Parameters of patients of all groups.

Mean age in group P50 was $37.6 \pm 6.13$ years (range 28-52), group P100 was 40.1 \pm 9.15 years (range 26-55) and in group P200 was 39.2 \pm 9.86 years (range 25-55) with $\mathrm{p}$ value of 0.546 . Out of 30 patients, in group P50 $14(46.7 \%)$ were males and $16(53.3 \%)$ were female, in group P100 17 (56.7\%) were males and 13 (43.3\%) were females, in group P200 16 (53.3) were males and 14 (46.7) were females. $P$ value $=0.732$. Mean weight in group P50 being 68.3 $\pm 5.86 \mathrm{~kg}$ (range 57-79), group P100 being $69.0 \pm 5.49 \mathrm{kgs}$ (range 58-77) and group P200 $68.5 \pm 6.67 \mathrm{~kg}$ (range 53-80) with a p value $=0$. 898. Mean height in group P50 being $163.2 \pm 5.29 \mathrm{~cm}$ (range 154174 ), group P200 being $162.1 \pm 3.03 \mathrm{cms}$ (range 156-168) and group P200 $163.8 \pm 4.27 \mathrm{cms}$ (range 157-175) with a p value of $=0.338$. Table 2 shows distribution of patients as per ASA status with 24 (80.0\%).

\begin{tabular}{|c|c|c|c|c|c|}
\hline \multirow{2}{*}{ Group } & \multicolumn{2}{|c|}{ ASA I } & \multicolumn{2}{|c|}{ ASA II } & \multirow{2}{*}{$P$-value } \\
\hline & No. & Percentage & No. & Percentage & \\
\hline $\mathrm{P} 50$ & 24 & 80 & 6 & 20 & \multirow{3}{*}{0.627} \\
\hline P100 & 22 & 73.3 & 8 & 26.7 & \\
\hline P200 & 25 & 83.3 & 5 & 16.7 & \\
\hline
\end{tabular}

Table 2: Distribution of patients as per ASA status.

Patients of group P50 in ASA I and 6 (20.0\%) in ASA II. In group P100 there were $23(73.3 \%)$ and $8(26.7 \%)$ patients in ASA I and ASA II. There were 25 (83.3\%) patients of group P200 in ASA I and 5 (16.7\%) patients with ASA II. When compared statistically P value of 0.627 was calculated.

Since, mean age, sex, weight, height and ASA status was comparable among all the three groups as statistically difference $P$ values were not significant. (All $P$ Value $=>0.05$ ) as shown in Table 1 . The mean total dose of Propofol used (mg) for induction among the studied groups was 101.2+7.79, in P50 (range 89-112), p-value $<0.001,152.7+7.71$ in P100 with (range 139-164), p value $<0.001$, and in group P200 the mean dosage was $207.4+8.06$ with a (range of 192-219), p -value $<0.001$. The difference was statistically significant with a $p$ value of $<0.05$ (Table 3 ). 


\section{Advances in Pharmacology and Clinical Trials}

\begin{tabular}{|c|c|c|c|c|c|}
\hline Propofol Amount (mg) & Mean & SD & Range & Comparison & P-value \\
\hline P50 & 101.2 & 7.79 & $89-112$ & P50 vs P100 & $<0.001^{*}$ \\
\hline P100 & 152.7 & 7.71 & $139-164$ & P100 vs P200 & $<0.001^{*}$ \\
\hline P200 & 207.4 & 8.06 & $192-219$ & P200 vs P50 & $<0.001^{*}$ \\
\hline
\end{tabular}

Table 3: Showing propofol amount (mg) during induction among various Groups.

The mean dose per kg body weight of Propofol used $(\mathrm{mg} / \mathrm{kg})$ for induction among the studied groups, in P50 was $1.49+0.029$ (range 1.2-1.8) with p- value $<0.001$, in P100 was $2.23+0.038$ (range $1.8-2.7$ ) with $\mathrm{p}$ value $<0.001$, and in group P200 the mean dosage was $3.07+0.061$ with a range of 2.4-4.1, $\mathrm{p}$ value $<0.001$. The difference was statistically significant $(\mathrm{p}$ value $<0.05)$ in all the groups (Table 4).

\begin{tabular}{|c|c|c|c|c|c|}
\hline Groups & $\mathbf{m g} / \mathbf{k g}$ & SD & Range & Comparison & P value \\
\hline P50 & 1.49 & 0.029 & $1.2-1.8$ & P50 vs P100 & $<0.001^{*}$ \\
\hline P100 & 2.23 & 0.038 & $1.8-2.7$ & P100 vs P200 & $<0.001^{*}$ \\
\hline P200 & 3.07 & 0.061 & $2.4-4.1$ & P200 vs P50 & $<0.001^{*}$ \\
\hline P50 & 1.49 & 0.029 & $1.2-1.8$ & P50 vs P100 & $<0.001^{*}$ \\
\hline
\end{tabular}

Table 4: Showing calculated propofol dose during induction $(\mathrm{mg} / \mathrm{kg})$ among various groups.

*Statistically Significant Difference (P-value $<0.05$ )

The mean induction time (seconds) among the studied groups was $121.9+8.26$ in P50 (range 107-134), p value $<0.001,89.4+6.51$ in P100 (range 78-99), p value $<0.001$ and in group P200 the mean time was $60.8+7.01$ (range $50-73), p$ value $<00.1$. The difference was statistically significant with a $p$ value of $<0.05$ (Table 5 ).

\begin{tabular}{|c|c|c|c|c|c|}
\hline \multirow{2}{*}{ Groups } & \multicolumn{3}{|c|}{ Induction time (seconds) } & \multirow{2}{*}{ Comparison } & \multirow{2}{*}{ P-value } \\
\cline { 2 - 4 } & Mean & SD & Range & & $<0.001^{*}$ \\
\hline P50 & 121.9 & 8.26 & $107-134$ & P50 vs P100 & $<0.001^{*}$ \\
\hline P100 & 89.4 & 6.51 & $78-99$ & P100 vs P200 & $<0.001^{*}$ \\
\hline P200 & 60.8 & 7.01 & $50-73$ & P200 vs P50 & \\
\hline
\end{tabular}

Table 5: Comparison based on induction time (seconds) among different groups.

*Statistically Significant Difference (P-value $<0.05)$

The mean systolic blood pressure $(\mathrm{mmHg})$ pre and post induction was $123.1+6.26$ and $109.8+5.13$ in P50, $122.6+4.50$ and $99.7+4.35$ in P200 and in group P200 was

$122.5+4.41$ and $91.1+3.89$ respectively. The difference was statistically significant with a p $<0.05$ (Table 6).

\begin{tabular}{|c|c|c|c|c|c|c|}
\hline \multirow{2}{*}{ Groups } & \multicolumn{4}{|c|}{ Systolic blood pressure (SBP) } & \multirow{3}{*}{ Diff. in SBP } & \multirow{2}{*}{ P-value (ANOVA) } \\
\cline { 2 - 5 } & \multicolumn{2}{|c|}{ Before Induction } & \multicolumn{2}{|c|}{ After Induction } & & \\
\cline { 2 - 5 } & Mean & SD & Mean & SD & & \multirow{2}{*}{$<0.001$} \\
\hline P50 & 123.1 & 6.26 & 109.8 & 5.13 & 13.3 & $22.9 *$ \\
\hline P100 & 122.6 & 4.5 & 99.7 & 4.35 & 31.5 & \\
\hline P200 & 122.5 & 4.41 & 91.1 & 3.89 & 3 \\
\hline
\end{tabular}

Table 6: Comparison of changes in systolic blood pressure ( $\mathrm{mmHg}$ ) before and after induction among different groups.

The mean diastolic blood pressure $(\mathrm{mmHg})$ pre and post induction was $81.6+3.99$ and $75.5+2.90$ in $\mathrm{P} 50$, 82.1+2.81and $74.8+1.89$ in $\mathrm{P} 100$ and $80.8+3.23$ and
$66.9+2.63$ in group P200 respectively. The difference was statistically significant with a $\mathrm{p}<0.001$ (Table 7 ). 


\section{Advances in Pharmacology and Clinical Trials}

\begin{tabular}{|c|c|c|c|c|c|c|}
\hline \multirow{3}{*}{ Groups } & \multicolumn{4}{|c|}{ Diastolic blood pressure (DBP) } & \multirow{3}{*}{ Diff. in DBP } & \multirow{3}{*}{ P-value (ANOVA) } \\
\hline & \multicolumn{2}{|c|}{ Before Induction } & \multicolumn{2}{|c|}{ After Induction } & & \\
\hline & Mean & SD & Mean & SD & & \\
\hline $\mathrm{P} 50$ & 81.6 & 3.99 & 75.5 & 2.9 & 6.1 & \multirow{3}{*}{$<0.001$} \\
\hline P100 & 82.1 & 2.81 & 74.8 & 1.89 & $11.0^{*}$ & \\
\hline P200 & 80.8 & 3.23 & 66.9 & 2.63 & $13.9^{* *}$ & \\
\hline
\end{tabular}

Table 7: Comparison of changes in diastolic blood pressure ( $\mathrm{mmHg}$ ) before and after induction among different groups. *Statistically Significant Difference (P-value $<0.05)$ Compared with P50

** Statistically Significant Difference (P-value $<0.05)$ Compared to P50 and P100

The mean arterial pressure $(\mathrm{mmHg})$ pre and post induction was $95.4+4.61$ and $86.9+3.52$ in $\mathrm{P} 50,95.6+3.25$ and $80.7+2.53$ in $\mathrm{P} 100$ and $94.7+3.52$ and $74.9+2.75$ in group P200 respectively. The difference was statistically significant with a $\mathrm{p}<0.05$ (Table 8 ).

\begin{tabular}{|c|c|c|c|c|c|c|}
\hline \multirow{3}{*}{ Groups } & \multicolumn{4}{|c|}{ Mean arterial pressure (MAP) } & \multirow{3}{*}{ Diff. in MAP } & \multirow{3}{*}{$\begin{array}{l}\text { P-value } \\
\text { (ANOVA) }\end{array}$} \\
\hline & \multicolumn{2}{|c|}{ Before Induction } & \multicolumn{2}{|c|}{ After Induction } & & \\
\hline & Mean & SD & Mean & SD & & \\
\hline $\mathrm{P} 50$ & 95.4 & 4.61 & 86.9 & 3.52 & 8.5 & \multirow{3}{*}{$<0.001$} \\
\hline $\mathrm{P} 100$ & 95.6 & 3.25 & 80.7 & 2.53 & $14.9^{*}$ & \\
\hline $\mathrm{P} 200$ & 94.7 & 3.52 & 74.9 & 2.75 & $19.8^{* *}$ & \\
\hline
\end{tabular}

Table 8: Comparison of changes in mean arterial pressure ( $\mathrm{mmHg}$ ) before and after induction among different groups. *Statistically Significant Difference (P-value $<0.05)$ Compared with P5

** Statistically Significant Difference (P-value<0.05) Compared to P50 and P100

There was no statistically significant difference between pre and post induction mean heart rate and oxygen saturation. The mean heart rate (bpm) pre and post induction was $87.9+4.40$ and $83.5+4.51$ in $\mathrm{P} 50$, $88.4+3.60$ and $83.6+3.70$ in P100 and $88.5+4.43$ and
$84.2+4.53$ in group $\mathrm{P} 200$ respectively ( $\mathrm{P}$ value $>0.05$ ). The mean oxygen saturation (\%) pre and post induction was $99.2+1.02$ and $98.1+1.12$ in $\mathrm{P} 200,98.6+1.0$ and $97.9+1.68$ in P100 and was 99.1+0.99 and 98.2+1.10 in group P200 respectively ( $P$ value $>0.05$ ) (Table 9 ).

\begin{tabular}{|c|c|c|c|c|c|c|}
\hline \multirow{2}{*}{ Groups } & \multicolumn{4}{|c|}{ Heart Rate (HR) } & \multirow{2}{*}{ Diff. in HR } & \multirow{2}{*}{$\begin{array}{c}\text { P-value } \\
\text { (ANOVA) }\end{array}$} \\
\cline { 2 - 5 } & \multicolumn{2}{|c|}{ Before Induction } & \multicolumn{2}{|c|}{ After Induction } & & \\
\cline { 2 - 5 } & Mean & SD & Mean & SD & & \multirow{2}{*}{0.861} \\
\hline P50 & 87.9 & 4.4 & 83.5 & 4.51 & 4.4 & \\
\hline P100 & 88.4 & 3.6 & 83.6 & 3.7 & 4.8 & \\
\hline P200 & 88.5 & 4.43 & 84.2 & 4.53 & 4.3 & \\
\hline
\end{tabular}

Table 9: Comparison of changes in heart rate (beats/min) before and after induction among different groups.

*Statistically Significant Difference (P-value $<0.05)$ Compared with P50

** Statistically Significant Difference (P-value $<0.05)$ Compared to P50 and P100

\section{Discussion}

In our study gender $\&$ age wise distribution, mean weight, mean height were all statistically comparable. This was consistent with findings of Sennur Uzun, et al. [24] who in their study of 72 patients showed mean age was $38 \pm 10$ in P200, $43 \pm 11$ in P300 and $40 \pm 14$ in P400, male to female ratio was $8 / 16$ in p200,12/12in p300 and7 /17 in p400. The mean weight was $70.7 \pm 14.4$ in $P$ $200,77.5 \pm 14.2$ in $P 300$ and $75.3 \pm 17.6$ in p400. The mean height was $165 \pm 9$ in p200, $169 \pm 11$ in p300 and $168 \pm 10$ in p400.

Statistical no significant difference was found between three groups $\mathrm{P}$ value $=0.627$ when patients were 


\section{Advances in Pharmacology and Clinical Trials}

distributed as per ASA status. Kazama T, et al. [2] in their study the subjects of the study were 250 patients classified as American Society of Anesthesiologists physical status I or II aged 25-55 years which is similar to our finding.

In our study it was observed that as the rate of infusion increased, larger Propofol doses were required which, in their study the total dose used was $(1.2,1.6$ and $2.5 \mathrm{mg} \mathrm{kg}-1$ in groups 1,2,3. respectively). Similar results were shown by Stokes DN, et al. [8] Sennur Uzun, et al \& Lie, et al. $[24,25]$ in their studies.

\begin{tabular}{|c|c|c|c|c|c|c|}
\hline \multirow{2}{*}{ Groups } & \multicolumn{4}{|c|}{$\mathbf{S P O}_{\mathbf{2}}$} & \multirow{2}{*}{ Diff.in spo2 } & \multirow{2}{*}{ P-value (ANOVA) } \\
\cline { 2 - 5 } & \multicolumn{2}{|c|}{ Before Induction } & \multicolumn{2}{|c|}{ After Induction } & & \\
\cline { 2 - 5 } & Mean & SD & Mean & SD & & \multirow{2}{*}{0.542} \\
\hline P50 & 99.2 & 1.02 & 98.1 & 1.12 & 1.1 & 0.8 \\
\hline P100 & 98.6 & 1 & 97.9 & 1.68 & 0.9 & \\
\hline P200 & 99.1 & 0.99 & 98.2 & 1.1 & 0.9 \\
\hline
\end{tabular}

Table 10: Comparison of changes in SPo2 before and after induction among different groups.

In our study the mean systolic blood pressure (mmHg), mean diastolic blood pressure \& mean arterial blood pressure (pre and post induction) was reduced as speed of injection increases from $50 \mathrm{mg} / \mathrm{min}$ to $100 \mathrm{mg} / \mathrm{min}$ to $200 \mathrm{mg} / \mathrm{min}$. Li Q, et al. [25] In their study showed decrease in systolic and diastolic arterial pressure was significantly less in the $300-\mathrm{ml} \mathrm{h}-1$ group at the end of induction and immediately after induction $(\mathrm{P}<$ 0.01). Sennur Uzun, et al. [24] in their study also observed a decrease in systolic, diastolic and mean arterial blood pressures with infusion rate of $200 \mathrm{ml} / \mathrm{h}, 300 \mathrm{ml} / \mathrm{hand}$ $400 \mathrm{ml} / \mathrm{h}$.

In our study, the mean heart rate (bpm) and mean oxygen saturation (\%) (Pre and post induction) showed no statistical significant change. This finding was supported by Rolly G, et al. [6] who also shows statistical insignificant changes in heart rate apnea, and saturation in their respective studies.

\section{Conclusion}

This study concludes that at faster speeds of injection of Propofol, larger doses are required for induction of anesthesia as compared to the doses required at slower speeds. Also, faster speeds of injection of propofol are associated with a significant drop in systolic, diastolic sand mean arterial pressures while as the time taken for induction of anesthesia was shorter when compared to the injection at slower speeds.
The mean induction time in our study was shorter in P200 when compared to P50 and P100 and the difference between three groups was statistically significant with $p$ value $<0.05$. This showed resemblance with the study conducted by Rolly G, et al. [6] who in their study showed mean induction time increased from 21.5 to 34.7 and 50.5 $\mathrm{s}$, when injection time was increased from 5 to 20 to $60 \mathrm{~s}$, respectively. Mean induction time in studies conducted by Sennur Uzun, et al \& Lie et al. $[24,25]$ is same as present in our study.
Limitations of this study were, injection of the drug manually to deliver it at accurate speeds is liable to errors, subjective assessment of induction by loss of verbal contact and small sample size.

\section{Acknowledgment}

The authors are highly thankful to the hospital administration, the paramedical staff of the anaesthetic department, hospital statistician, and computer operators for helping in conducting this research.

\section{References}

1. Sebel PS, Lowdon JD (1989) Propofol, a new intravenous anaesthetic. Anesthesiology 71(2): 260277.

2. Kazama T, Ikeda K, Morita K, Ikeda T, Kikura M, et al. (2001) Relation between initial blood distribution volume and Propofol induction dose requirement. Anesthesiology 94: 205-210.

3. Adachi YU, Watanabe K, Higuchi H, Satoh S (2001) The determinants of Propofol induction of anaesthesia dose. Anesth Analg 92(3): 656-661.

4. Kazama T, Ikeda K, Morita K, Kikura M, Ikeda T, et al. (2000) Investigation of effective anaesthesia induction doses using a wide range of infusion rates 


\section{Advances in Pharmacology and Clinical Trials}

with undiluted and diluted Propofol. Anesthesiology 92(4): 1017-1028.

5. Gillies GW, Lees NW (1989) The effects of speed of injection on induction with Propofol. A comparison with etomidate. Anaesthesia 44(5): 386-388.

6. Rolly G, Versichelen L, Huyghe L, Mungroop H (1985) Effects of speed of injection on induction of anaesthesia using Propofol. Br J Anaesth 57(8): 743746.

7. Blum J, Kochs Eberhard, Forster N, Schneider G (2006) The influence of injection rate on the hypnotic effect of Propofol during anesthesia: A randomised trial. PLoS Clin Trials 28: e17.

8. Stokes DN, Hutton P (1991) Rate dependent induction phenomena with Propofol: Implications for the relative potency of intravenous anesthetics. Anesth Analg 72(5): 578-583.

9. Ludbrook GL, Upton RN (1997) A physiological model of induction of anaesthesia with Propofol in sheep. 2. Model analysis and implications for dose requirement. Br J Anaesth 79(4): 505-513.

10. Ludbrook GL, Upton RN, Grant C, Martinez AM (1999) Cardiac output is a determinant of the initial concentrations of Propofol after short-infusion administration. Anesth Analg 89: 545-552.

11. Robinson B, Ebert T, O'Brien T, Colinco MD, Muzi M (1997) Mechanisms whereby Propofol mediates peripheral vasodilation in humans. Anesthesiology 86: 64-72.

12. Larijani G, Gratz I, Afshar M, Jacobi AG (1989) Clinical pharmacology of Propofol: an intravenous anesthetic agent. DICP 23(10): 743-749.

13. Sebel P, Lowdon J (1987) Propofol: a new intravenous anesthetic. Anesthesiology 71: 260-277.

14. (1987) New awakening in anaesthesia-at a price. Lancet 8548: 1469-1470.

15. (1990) Propofol. Med Lett Drugs Ther 32: 22.
16. Caleys MA, Gepts E, Camu F (1988) Hemodynamic changes during anesthesia induced and maintained with Propofol. Br J Anaesth 60(1): 3- 9.

17. Cheng TH, Chen JJ, Chen CH, Wong KL (2009) Effects of Propofol on cyclic strain-induced endothelin-1 expression in human umbilical vein endothelial cells. Anesthesiology 110(1): 74-80.

18. Tramer MR, Moore RA, McQuay HJ (1997) Propofol and bradycardia: causation, frequency and severity. Br J Anaesth 78(6): 642-651.

19. Ebert TJ, Muzi M, Berens R, Goff D, Kampine JP (1992) Sympathetic response to induction of anesthesia in humans with Propofol or etomidate. Anesthesiology 76(5): 725-733.

20. Kanto J, Gepts E (1989) Pharmacokinetic implications for the clinical use of Propofol. Clin Pharmacokinet 17(5): 308-326.

21. Wagner B, Berman S, Devitt P, O Hara DA (1994) Retrospective analysis of postoperative nausea and vomiting to determine antiemetic activity of droperidol added to Propofol: a possible drug interaction. Pharmacotherapy 14(5): 586-591.

22. Liu SH, Wei W, Ding GN, Ke JD, Hong FX, et al. (2009) Relationship between depth of anesthesia and effectsite concentration of Propofol during induction with the target- controlled infusion technique in elderly patients. Chin Med J (Engl) 122(8): 935-940.

23. Machata AM, Willschke $H$, Kabon B, Kettner SC, Marhofer P (2008) Propofol-based sedation regimen for infants and children undergoing ambulatory magnetic resonance imaging. British Journal of Anaesthesia 101(2): 239-243.

24. Sennur Uzun, Burcu Akbay Ozkaya, Omer Savas Yilbas, Banu Ayhan, Altan Sahin, et al. (2011) Effects of different Propofol injection speeds on blood pressure, dose, and time of induction. Turk J Med Sci 41(3): 397-401.

25. Li Q, Zhou Q, Xiao W, Zhou H (2016) Determination of the appropriate propofol infusion rate for outpatient upper gastrointestinal endoscopy-a randomized prospective study. BMC Gastroenterology 16(1): 49.

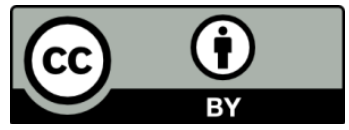

Bhat JA, et al. Effect of Various Injection Speeds of Propofol on Blood Pressure, Time Taken and Dose Required for Induction of Anesthesia: A Prospective Observational Study. Adv Pharmacol Clin Trials 2018, 3(3): 000133. 